\title{
Nationwide Mortality Data after Flow-Diverting Stent Implantation in Korea
}

\author{
Tackeun Kim, M.D., ${ }^{1,2}$ O-Ki Kwon, M.D., Ph.D., ${ }^{1,2}$ Heeyoung Lee, M.D., Ph.D., ${ }^{2,3}$ Min Jai Cho, M.D., ${ }^{1,2}$ Hyun Jean Jeong, M.D., ${ }^{1,2}$ \\ Seung Pil Ban, M.D., ${ }^{1,2}$ \\ Department of Neurosurgery, Seoul National University Bundang Hospital, Seongnam, Korea \\ Seoul National University College of Medicine, ${ }^{2}$ Seoul, Korea \\ Center for Preventive Medicine and Public Health, ${ }^{3}$ Seoul National University Bundang Hospital, Seongnam, Korea
}

Objective : To investigate nationwide statistics on flow-diverting stent usage for cerebral aneurysm treatment and related mortality data.

Methods : We requested data extraction from the National Health Insurance Service claims database using electronic data interchange codes (J3207064, J3207073). Patient and hospital information as well as death statistics were collected from the database.

Results : A total of 169 procedures were performed using flow-diverting stents for cerebral aneurysm treatment from November 2014 to December 2016 in Korea. The majority of primary diagnosis was unruptured intracranial aneurysm. During the study period, nine subjects died, including one patient initially diagnosed with subarachnoid hemorrhage. The crude mortality rate was $5.3 \%$. Five patients died within one month after the procedure; therefore, the estimated periprocedural mortality rate was $3.0 \pm 1.3 \%$. The mortality rate as of the last day of 2016 was $6.3 \pm 2.1 \%$.

Conclusion : In a 171 person-year follow-up in a Korean series, nine deaths occurred after flow-diverting stent treatment. The crude mortality rate in Korea (5.3\%) was higher than that reported in a previous meta-analysis (3.8\%).

Key Words : Intracranial aneurysm · Korea · Mortality · Stents · Flow diverting stent · Flow diverter.

\section{INTRODUCTION}

Intracranial aneurysm (IA) causes subarachnoid hemorrhage (SAH), which can be fatal. The standardized incidence of IA in Korea was 52.2 per 100,000 person-years, and more than half were diagnosed as unruptured intracranial aneurysm (UIA) ${ }^{4}$. Although clipping of an aneurysm had been regarded as the treatment of choice, endosaccular coil embolization has also become a standard treatment option since the International Subarachnoid Aneurysm Trial Collaborative Group reported promising results for endovascular treatment of $\mathrm{IA}^{5)}$. Development of innovative endovascular devices such as intracranial stents has promoted the extension of indications for endovascular IA treatment. The flow-diverting stent (FDS) is among the

- Received : July 24, 2017 • Accepted : September 2, 2017

- Address for reprints : 0-Ki Kwon, M.D., Ph.D.

Department of Neurosurgery, Seoul National University Bundang Hospital, 82 Gumi-ro 173beon-gil, Bundang-gu, Seongnam 13620, Korea Tel : +82-31-787-7163, Fax : +82-31-787-4059, E-mail : kwonoki@snu.ac.kr

This is an Open Access article distributed under the terms of the Creative Commons Attribution Non-Commercial License (http://creativecommons.org/licenses/by-nc/4.0) which permits unrestricted non-commercial use, distribution, and reproduction in any medium, provided the original work is properly cited. 
valuable innovations in the field of endovascular neurosurgery $^{3}$. The concept of management had shifted from endosaccular to endoluminal treatment. However, the literature regarding FDS use has reported high neurological morbidity and mortality rates ${ }^{7)}$.

In Korea, the FDS has been covered by the National Health Insurance Service (NHIS) since November 2014 using the following criteria : 1) UIA diameter $15 \mathrm{~mm}$ or larger, or 2) blister aneurysm of the internal carotid artery, dissecting aneurysm of the vertebral artery, or fusiform aneurysm, each measuring less than $15 \mathrm{~mm}$. Thus, we designed this study to investigate nationwide statistics on FDS usage based on claims data from the NHIS, a universal medical insurer in Korea. In addition, we analyzed mortality data after FDS treatment using death statistics provided by the NHIS.

\section{MATERIALS AND METHODS}

\section{Data acquisition}

The NHIS review board approves selective claims data requests for research purposes. Because this public database is anonymized, institutional approval was waived by the institutional review board (X-1703-388-906). We requested data extraction using electronic data interchange (EDI) codes J3207064 (Surpass flow diverter; Stryker, Kalamazoo, MI, USA) and J3207073 (Pipeline embolization device; Medtronic, Minneapolis, MN, USA). Other FDS devices were not coded in the Korean EDI system.

All medical expenditures through December 31, 2016 were extracted, including previous use for any subject treated with an FDS. Information about hospital claims data were also recorded. Demographic data of patients including sex, age, short address, income level, and survival status were collected for the day of treatment.

\section{Statistical analysis}

Open-source statistical software R version 3.4.0 (R Foundation for Statistical Computing, http://www.r-project.org) was used for statistical analysis. Kaplan-Meier survival analysis was performed to estimate mortality over time after a procedure using relevant packages (survival, https://cran.r-project.org/ package=survival; survminer, https://cran.r-project.org/package=survminer).

\section{RESULTS}

\section{Patients}

Among 169 patients, 116 were female (68.6\%). Seventeen patients $(10.1 \%)$ were $<40$ years old at the time of treatment, while 78 (46.2\%) were $\geq 60$ years old. The remaining 74 patients (43.8\%) were between 40 and 59 year-old. As age data were provided by age group, mean and standard deviation could not be determined.

The most common diagnosis code linked with FDS was UIA $(n=132,78.1 \%)$, followed by unruptured dissection $(n=27,16.0 \%)$ and SAH ( $\mathrm{n}=10,5.9 \%)$. The prevalence of hypertension, diabetes, and dyslipidemia was $70.4 \%, 31.4 \%$, and $62.1 \%$, respectively.

Originally, income level was divided into 20 grades; 20 was highest and level 0 referred to the medical assistance group. We divided income level into lowermost, lower, upper, and uppermost quartiles, excluding the medical assistance group. Case numbers were directly proportional to quartile income level. Sixty (35.5\%) patients were in the uppermost quartile, whereas 34 (20.1\%), 31 (18.3\%), and 23 (13.6\%) were in upper, lower, and lowermost quartiles, respectively. Twenty-one (12.4\%) were medical assistance patients. Most patients presented to the outpatient clinic on the initial visit to the hospital ( $\mathrm{n}=157,92.9 \%)$. Only 12 patients were admitted via the emergency department (7.1\%). Mean duration of hospital stay was $10.4 \pm 8.2$ days. Patient characteristics are summarized in Table 1.

The most frequent residence address was Seoul ( $\mathrm{n}=37,21.9 \%)$, followed by Gyeonggi-do province ( $\mathrm{n}=34,20.1 \%)$, Busan $(\mathrm{n}=24$, $14.2 \%)$, and Gyeongsangnam-do province $(\mathrm{n}=15,8.9 \%)$, respectively (Table 2).

\section{Procedure statistics}

From November 2014 to December 2016, a total 169 procedures were performed using the Pipeline embolization device in 169 patients. There were no records of Surpass flow-diverter use. Eighty-three and 73 procedures were performed in 2015 and 2016, respectively. The average number of procedures was $6.5 \pm 2.1$ per month. The majority of procedures $(n=130,76.9 \%)$ were performed in tertiary referral hospitals, with the rest $(n=39$, 23.1\%) in general hospitals. Among all claims data, most were issued by a department of neurosurgery ( $\mathrm{n}=166,98.2 \%)$, with a single case each by departments of internal medicine, neu- 
Mortality after Flow-Diverting Stent | Kim T, et al.

Table 1. Patient characteristics

\begin{tabular}{|c|c|}
\hline & Value \\
\hline \multicolumn{2}{|l|}{ Sex } \\
\hline Male & $53(31.4)$ \\
\hline Female & $116(68.6)$ \\
\hline \multicolumn{2}{|l|}{ Age group (years) } \\
\hline $0-29$ & $4(2.4)$ \\
\hline $30-39$ & $13(7.7)$ \\
\hline $40-49$ & $13(7.7)$ \\
\hline $50-59$ & $61(36.1)$ \\
\hline $60-69$ & $49(29.0)$ \\
\hline 70 and over & $29(17.2)$ \\
\hline \multicolumn{2}{|l|}{ Diagnosis } \\
\hline Unruptured aneurysm & $132(78.1)$ \\
\hline Unruptured dissection & $27(16.0)$ \\
\hline Subarachnoid hemorrhage & $10(5.9)$ \\
\hline \multicolumn{2}{|l|}{ Co-morbidity } \\
\hline Hypertension & $119(70.4)$ \\
\hline Diabetes mellitus & $53(31.4)$ \\
\hline Dyslipidemia & $105(62.1)$ \\
\hline \multicolumn{2}{|l|}{ Income level } \\
\hline Medical assistance group & $21(12.4)$ \\
\hline Lowermost & $23(13.6)$ \\
\hline Lower & $31(18.3)$ \\
\hline Upper & $34(20.1)$ \\
\hline Uppermost & $60(35.5)$ \\
\hline \multicolumn{2}{|l|}{ Admission route } \\
\hline Outpatient clinic & $157(92.9)$ \\
\hline Emergency department & $12(7.1)$ \\
\hline \multicolumn{2}{|l|}{ Inpatient duration } \\
\hline Less than 1 week & $73(43.2)$ \\
\hline 2-4 weeks & $91(53.8)$ \\
\hline Over 1 month & $5(3.0)$ \\
\hline
\end{tabular}

Values are presented as number (\%)

rology, and rehabilitation medicine. More than half of the procedures were performed in Seoul $(\mathrm{n}=89,52.7 \%)$, followed by Gyeonggi-do province ( $n=22,13.0 \%)$, Busan ( $n=20,11.8 \%$ ), and Ulsan $(n=17,10.1 \%)$, in accordance with the location of hospitals (Table 2).

\section{Mortality after FDS treatment}

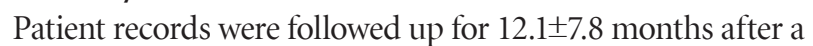
procedure. Thus, the total observation size was 171 person-
Table 2. Nationwide distribution of patients and case numbers

\begin{tabular}{lcc}
\hline & Patients & Procedures \\
\hline Seoul & $37(21.9)$ & $89(52.7)$ \\
\hline Busan & $24(14.2)$ & $20(11.8)$ \\
\hline Daegu & $3(1.8)$ & \\
Incheon & $6(3.6)$ & \\
Gwangju & $5(3.0)$ & \\
\hline Daejeon & $5(3.0)$ & $17(10.1)$ \\
\hline Ulsan & $6(3.6)$ & $22(13.0)$ \\
\hline Gyeonggi-do & $34(20.1)$ & $8(1.2)$ \\
Gangwon-do & $5(3.0)$ & $3(1.8)$ \\
\hline Chungcheongbuk-do & $4(2.4)$ & $3(1.8)$ \\
\hline Chungcheongnam-do & $5(3.0)$ & $5(3.0)$ \\
\hline Jeollabuk-do & $3(1.8)$ & \\
\hline Jeollanam-do & $4(2.4)$ & \\
\hline Gyeongsangbuk-do & $6(3.6)$ & \\
\hline Gyeongsangnam-do & $15(8.9)$ & $1(0.6)$ \\
\hline Jeju & $6(3.6)$ & \\
\hline Unidentified & & \\
\hline Values & & \\
\hline
\end{tabular}

Values are presented as number (\%)

years. During the observation period, 9 patients died. Among mortality cases, eight (88.9\%) were initially treated for a diagnosis of UIA. A single patient diagnosed with SAH underwent FDS placement and died 21 days after the procedure.

Within one month after the procedure, five patients including one SAH patient died, and the estimated mortality rate was $3.0 \pm 1.3 \%$. At 1-year after the procedure, the mortality rate was $5.2 \pm 1.8 \%$, based on eight deaths. The mortality rate as of the last day of 2016 was $6.3 \pm 2.1 \%$ (Fig. 1).

\section{DISCUSSION}

Preventive treatment for UIA should be recommended based on estimated rupture risk and procedure-related risk. In considering the life-long rupture risk of a UIA, we must evaluate the long-term adverse effect of each treatment modality, as well as the periprocedural risk. Although long-term efficacy and safety of aneurysm clipping or endosaccular coiling are relatively well known, we know little about FDS use. A recent meta-analysis reported FDS-related mortality as 3.8\% and morbidity as $9.8 \%$ among 2826 aneurysms ${ }^{7}$. The Pipeline for 


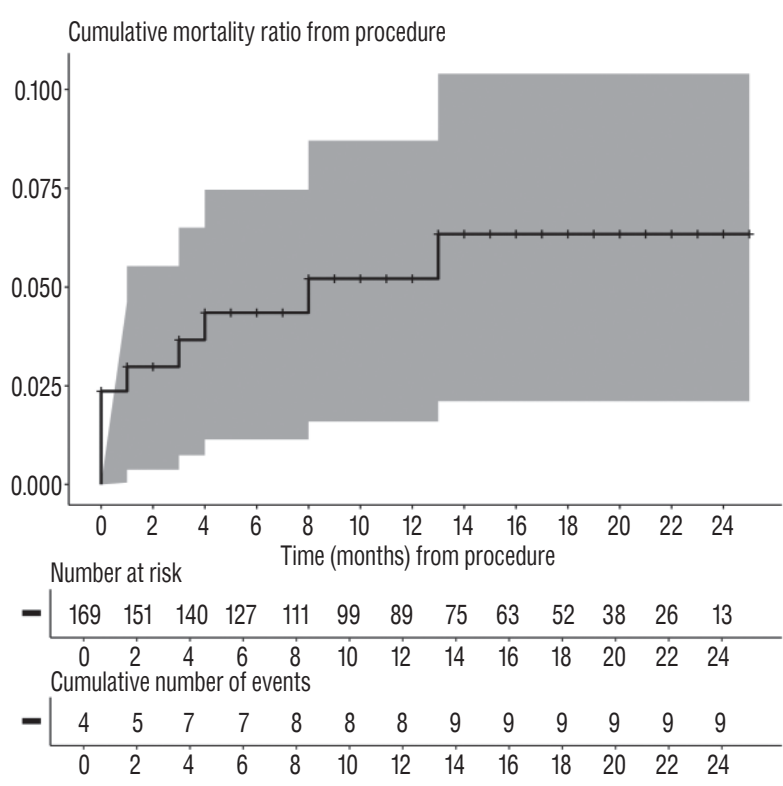

Fig. 1. Kaplan-Meier curve represents mortality after flow-diverting stent procedure. Solid line indicates mortality rate over time, and gray shading shows $95 \%$ confidence interval.

Uncoilable or Failed Aneurysms study showed a 3.7\% crude mortality after FDS treatment for complex internal carotid artery aneurysms $s^{1)}$.

In this investigation, we estimated mortality after FDS treatment in Korea. More than $94 \%$ of patients underwent FDS for the diagnosis of UIA. Furthermore, more than $92 \%$ of patients initially presented to hospitals via the outpatient clinic. In sum, most patients were treated electively. An all-inclusive dataset recorded a $6.3 \%$ mortality rate during a mean follow-up of 12.1 months. Based on the NHIS coverage criteria, the treated aneurysms might have been larger and more complex than those usually treated.

To judge acceptable risk, we should consider the natural history of UIAs, especially those that are larger or more complex. The natural course of aneurysms was reported by several previous studies. One large cohort study in Korea reported an annual UIA rupture risk of $1.0 \%$, regardless of size and location. Notably, the annual rupture risk of a UIA larger than $7 \mathrm{~mm}$ in any location was $1.7 \%{ }^{2}$. In another prospective cohort study of internal carotid artery aneurysms in Japan, a UIA measuring 7-24 mm had a 1.1-1.2\% annual rupture rate ${ }^{6}$. The rupture risk of giant $(\geq 25 \mathrm{~mm})$ internal carotid UIAs was $10.6 \%$.

A critical limitation of this study was linked to the limitations of the NHIS database. First, due to the nature of a claims database, image archiving was not available. Thus, we could not identify the location, size, and shape of aneurysms, which are important factors related to rupture risk and procedurerelated risk. Second, as the database did not include medical records, detailed information about aneurysm-related symptoms was absent. Similarly, neurologic morbidity caused by the FDS could not be captured in the NHIS database.

Although we could identify the date of death, the cause of death was masked as sensitive personal information by the NHIS. However, the date of death was accurate. In Korea, every death must be reported by law, and government offices share death statistics with the NHIS.

\section{CONCLUSIONS}

During a 171 person-year follow-up in a Korean series, nine deaths occurred after FDS treatment. The crude mortality rate in Korea (5.3\%) was higher than reported in a previous metaanalysis (3.8\%). Estimated mortality using survival analysis was $6.3 \pm 2.1 \%$ at the end of the study period.

\section{CONFLICTS OF INTEREST}

The authors have no financial conflicts of interest.

\section{INFORMED CONSENT}

This type of study does not require informed consent.

\section{- Acknowledgements}

This study used NHIS-NSC data (NHIS-2017-1-160) compiled by the NHIS. The authors declare that they have no conflicts of interest.

\section{References}

1. Becske T, Brinjikji W, Potts MB, Kallmes DF, Shapiro M, Moran CJ, et al. : Long-term clinical and angiographic outcomes following pipeline embolization device treatment of complex internal carotid artery aneurysms: five-year results of the pipeline for uncoilable or failed aneurysms trial. 
Neurosurgery $80: 40-48,2017$

2. Byoun HS, Huh W, Oh CW, Bang JS, Hwang G, Kwon OK : Natural history of unruptured intracranial aneurysms : a retrospective single center analysis. J Korean Neurosurg Soc 59 : 11-16, 2016

3. Fiorella D, Woo HH, Albuquerque FC, Nelson PK : Definitive reconstruction of circumferential, fusiform intracranial aneurysms with the pipeline embolization device. Neurosurgery 62 : 1115-1120; discussion 11201111,2008

4. Kim T, Lee H, Ahn S, Kwon OK, Bang JS, Hwang G, et al. : Incidence and risk factors of intracranial aneurysm: a national cohort study in Korea.

Int J Stroke 11 : 917-927, 2016
5. Molyneux A, Kerr R, Stratton I, Sandercock P, Clarke M, Shrimpton J, et al. : International subarachnoid aneurysm trial (ISAT) of neurosurgical clipping versus endovascular coiling in 2143 patients with ruptured intracranial aneurysms: a randomised trial. Lancet 360 : 1267-1274, 2002

6. UCAS Japan Investigators; Morita A, Kirino T, Hashi K, Aoki N, Fukuhara $S$, et al. : The natural course of unruptured cerebral aneurysms in a Japanese cohort. N Engl J Med 366 : 2474-2482, 2012

7. Ye G, Zhang M, Deng L, Chen X, Wang Y : Meta-analysis of the efficiency and prognosis of intracranial aneurysm treated with flow diverter devices. J Mol Neurosci 59 : 158-167, 2016 